\title{
Poly(3-phenylgalvinoxylthiophene). A New Conjugated Polyradical with High Spin Concentration
}

\author{
Makoto MIYASAKA, Tomoko YAMAZAKI, and Hiroyuki NiSHIDE ${ }^{\dagger}$ \\ Department of Applied Chemistry, Waseda University, Shinjuku, Tokyo 169-8555, Japan
}

(Received June 18, 2001; Accepted September 15, 2001)

\begin{abstract}
Di-tert-butyl-4-acetoxyphenyl)(3,5-di-tert-butyl-4-oxocyclohexa-2,5-diene-1-ylidene)methyl]phenyl $\}$ thiophene (2a) was synthesized and oxidatively polymerized with ferric chloride at low temperature to yield poly(3-\{4-[(3,5-di-tert-butyl-4-acetoxyphenyl)(3,5-di-tert-butyl-4-oxocyclohexa-2,5-diene-1-ylidene)methyl]phenyl $\}$ thiophene) (1a). Head-to-tail content of 1 a with a molecular weight of $>10^{4}$ reached $92 \%$. This polymer has a quinoid chromophore, and it reversibly showed a dark blue and red brownish color ascribed to an anion and a radical form, respectively. The polyradical $\mathbf{1}$ was almost quantitatively generated from $\mathbf{1 b}$ (a spin concentration of 0.9 spin/galvinoxyl unit), which was persistent at room temperature. The SQUID measurement at low temperature gave a spin quantum number $(S)$ of $1 / 2$ for $\mathbf{1}$, which indicated a paramagnetic ground state. $\mathbf{1}$ doped with iodine showed an electrical conductivity of $10^{-5} \mathrm{~S} \mathrm{~cm}^{-1}$. The polyradical derivatives, 7 and $\mathbf{8}$, displayed $S$ of $1 / 2-2 / 2$ and $1 / 2$, respectively, and an electrical conductivity of $10^{-4}-10^{-3} \mathrm{~S} \mathrm{~cm}^{-1}$ after doping.

KEY WORDS $\pi$-Conjugated Polymer / Polythiophene / Oxidative Polymerization / Polyradical / Galvinoxyl / Magnetic Property /
\end{abstract}

There has been current interest in the synthesis of organic polymers bearing a stable radical or a paramagnetic repeating unit. ${ }^{1}$ Among them, ferromagnetic behavior could be expected for $\pi$-conjugated polyradicals which satisfy the $\pi$-conjugation requirements of a non-Kekulé and non-disjoint connectivity. We have synthesized pendant-type polyradicals, e.g., poly(phenylacetylene) $\mathrm{s}^{2}$ and poly(1,2-phenylenevinylene)s bearing $\pi$-conjugated 2,6-di-tert-butylphenoxyl, ${ }^{3 \text { a }} \mathrm{N}$-tertbutylnitroxide, ${ }^{3 \mathrm{~b}}$ and galvinoxyl, ${ }^{3 \mathrm{c}}$ and reported their ferromagnetic property. Miura et al. also reported $\mathrm{N}$-tert-butylnitroxide and nitronylnitroxide based on poly(phenylacetylene), ${ }^{4 \mathrm{a}}$ poly(1,3-phenylene) ${ }^{4 \mathrm{~b}}$ and poly(1,3-phenyleneethynylene). ${ }^{4 \mathrm{c}}$ Polythiophene-based polyradicals have been synthesized by Yamamoto et $a l^{5}$ and Lahti et al. ${ }^{6}$

Poly(3-substituted thiophene)s have been extensively investigated for their practical and potential applications for electronic and photonic materials and devices, ${ }^{7}$ because they are characterized by low band-gap, good solvent-solubility, and processability. Many regioselective poly(3-substituted-thiophene)s have been synthesized with reductive methods using metal catalysts. ${ }^{8}$ On the contrary, Anderson et al. ${ }^{9}$ reported an oxidative coupling polymerization for the regioselective synthesis of high molecular weight poly(3alkylphenylthiophene) using a slurry of $\mathrm{FeCl}_{3}$ in chloroform. Ueda et al. ${ }^{10}$ much improved this regioselective oxidative polymerization of 3-alkylthiophenes by applying the polymerization conditions of dilute

${ }^{\dagger}$ To whom correspondence should be addressed. monomer concentration and low temperature. We recently succeeded in the synthesis of high molecular weight and regioregular poly[3-(3,5-di-tert-butyl4-phenoxyl)thiophene] (4), and reported its ferromagnetic or high-spin ground state. ${ }^{11}$ We also reported poly\{3-[bis(4-tert-butylphenyl)amino]- and -[( $N$-tertbutyl- $N$-tert-butyldimethylsiloxy)amino]-thiophene $\}$, which however remained oligomers. ${ }^{12}$ Based on these previous results, we selected, in this paper, galvinoxyl, i.e., 2,6-di-tert-butyl-4-(3,5-di-tert-butyl-4oxocyclohexa-2,5-dienylidenemethyl)phenoxyl, as the pendant radical species to be introduced to the polythiophene backbone. (1) (Chart 1). The galvinoxyl radical is typical as a persistent organic radical due to an effective spin localization on the galvinoxyl unit; it is easy to handle at room temperature even under air. It is often studied as a building component for purely organic magnetic materials, such as a ferromagnetic mixed crystal of the galvinoxyl radical and hydrogalvinoxyl. ${ }^{13 \mathrm{c}}$ This paper describes our new $\pi$-conjugated pendanttype polyradical composed of polythiophene as a backbone and of phenylgalvinoxyl as a 3-substituted pendant radical, respectively.

\section{EXPERIMENTAL}

\section{Synthesis}

4-Bromo-[(3,5-di-tert-butyl-4-hydroxyphenyl)(3,5-ditert-butyl-4-oxo-cyclohexa-2,5-diene-1-ylidene)methyl]benzene (3b). A hexane solution of $1.5 \mathrm{M}$ butyllithium $(28.4 \mathrm{~mL}, 42.6 \mathrm{mmol})$ was added to (4-bromo- 


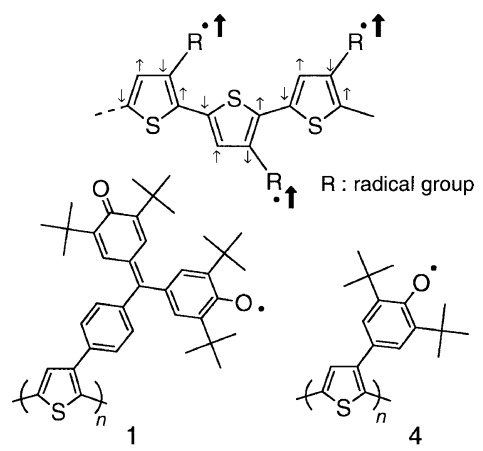

Chart 1.

2, 6 - di - tert - butylphenoxy)trimethylsilane ${ }^{3 \mathrm{a}} \quad(15.0 \mathrm{~g}$, $41.9 \mathrm{mmol})$ in dry THF $(84 \mathrm{~mL})$ at $-78^{\circ} \mathrm{C}$. The solution was stirred for $0.5 \mathrm{~h}$ at $-78^{\circ} \mathrm{C}$, and then $N, N, N^{\prime}, N^{\prime}$-tetramethylethylenediamine $(6.9 \mathrm{~mL})$ and methyl 4-bromobenzoate $(4.1 \mathrm{~g}, 19.1 \mathrm{mmol})$ in dry THF $(19.1 \mathrm{~mL})$ were added. The mixture was allowed to warm to ambient temperature overnight. Then potassium hydroxide $(6.9 \mathrm{~g})$ in $19.1 \mathrm{~mL}$ water was added to the solution which was stirred for $24 \mathrm{~h} .{ }^{13 a}$ The solution was washed with aqueous ammonium chloride and water, then extracted with chloroform. The chloroform layer was dried over anhydrous sodium sulfate. After filtration and evaporation, the crude product was purified by chromatography on silica gel with a hexane/chloroform (1/2) eluent. Recrystallization from hexane/chloroform (8/2) gave the title compound as orange crystals: yield $54 \%$; Mp $266-267^{\circ} \mathrm{C}$; ${ }^{1} \mathrm{HNMR}\left(\mathrm{CDCl}_{3}, 500 \mathrm{MHz}\right): \delta 1.25(\mathrm{~s}, 9 \mathrm{H}$, quinone tert-Bu), $1.28(\mathrm{~s}, 9 \mathrm{H}$, quinone tert-Bu), $1.41(\mathrm{~s}, 18 \mathrm{H}$, tert-Bu), $5.52(\mathrm{~s}, 1 \mathrm{H}, \mathrm{OH}), 7.00(\mathrm{~s}, 2 \mathrm{H}, \mathrm{Ph}), 7.07$ (d, $1 \mathrm{H}, 2.8 \mathrm{~Hz}$, quinone), $7.15(\mathrm{~d}, 2 \mathrm{H}, 8.5 \mathrm{~Hz}, \mathrm{Ph})$, $7.22(\mathrm{~d}, 1 \mathrm{H}, 2.8 \mathrm{~Hz}$, quinone), $7.54(\mathrm{~d}, 2 \mathrm{H}, 8.5 \mathrm{~Hz}$, $\mathrm{Ph}),{ }^{13} \mathrm{CNMR}\left(\mathrm{CDCl}_{3}\right): \delta 29.53,29.65,30.27,34.39$, $35.25,34.31,123.64,129.03,129.95,131.05,131.47$, $131.93,132.48,133.76,135.43,140.09,147.00$, 155.58, 156.28, 186.07.; IR (KBr pellet, $\mathrm{cm}^{-1}$ ): 3634 $\left(v_{\mathrm{O}-\mathrm{H}}\right), 1603$ (quinone, $\left.v_{\mathrm{C}=\mathrm{C}}\right) \mathrm{MS}(\mathrm{m} / \mathrm{z}): 576,578$ $\left(\mathrm{M}^{+}, \mathrm{M}^{+}+2\right)$, calcd for $\mathrm{M}=577.6$. Anal. Calcd for $\left(\mathrm{C}_{35} \mathrm{H}_{45} \mathrm{BrO}_{2}\right)$ : C, 72.8; H, 7.9; $\mathrm{Br}, 13.8$. Found: $\mathrm{C}$, 71.8; H, 8.2; Br, 13.6.

4-Bromo-[(3,5-di-tert-butyl-4-acetoxyphenyl) (3,5-ditert-butyl-4-oxo-cyclohexa-2,5-diene-1-ylidene)methyl]benzene (3a). $4.5 \mathrm{~g}(7.79 \mathrm{mmol})$ of $\mathbf{3 b}$ was dissolved in $191 \mathrm{~mL}$ of acetic anhydride, and one drop of perchloric acid was added. The solution was stirred for $15 \mathrm{~h}$ at room temperature, and unreacted acetic anhydride was hydrolyzed by adding excess water. The mixture was extracted with ether, and washed with water. The ether layer was dried over anhydrous sodium sulfate and evaporated, and the crude product was purified by chromatography on silica gel with a hexane/chloroform
(1/2) eluent. Recrystallization from hexane/chloroform (9/1) gave the title compound as orange crystals: yield 72\%; Mp 236-238 ${ }^{\circ} \mathrm{C} ;{ }^{1} \mathrm{HNMR}\left(\mathrm{CDCl}_{3}, 500 \mathrm{MHz}\right): \delta$ $1.24(\mathrm{~s}, 9 \mathrm{H}$, quinone tert-Bu), $1.25(\mathrm{~s}, 9 \mathrm{H}$, quinone tert$\mathrm{Bu}), 1.31\left(\mathrm{~s}, 18 \mathrm{H}\right.$, tert-Bu), $2.37\left(\mathrm{~s}, 3 \mathrm{H}, \mathrm{OCOCH}_{3}\right)$, 7.11(d, 1H, 2.7 Hz, Ph), 7.13 (s, 2H, Ph), 7.15 (d, 2H, $8.5 \mathrm{~Hz}, \mathrm{Ph}), 7.17$ (d, $1 \mathrm{H}, 2.7 \mathrm{~Hz}$, quinone), 7.55 (d, $2 \mathrm{H}$, $8.5 \mathrm{~Hz}, \mathrm{Ph}) ;{ }^{13} \mathrm{C} \mathrm{NMR}\left(\mathrm{CDCl}_{3}\right): \delta 22.64,29.52,29.58$, $31.40,35.30,35.33,23.75,129.95,130.44,131.19$, $131.63,131.93,133.62,137.04,139.62,142.37$, 147.60, 149.25, 154.63, 170.61, 186.19.; IR (KBr pellet, $\mathrm{cm}^{-1}$ ): 1764 (acetyl, $v_{\mathrm{C}=\mathrm{O}}$ ), 1609 (quinone, $v_{\mathrm{C}=\mathrm{C}}$ ); MS (m/z): 618, $620\left(\mathrm{M}^{+}, \mathrm{M}^{+}+2\right)$, calcd for $\mathrm{M}=619.7$. Anal. Calcd for $\left(\mathrm{C}_{37} \mathrm{H}_{47} \mathrm{BrO}_{3}\right)$ : C, 71.7; $\mathrm{H}, 7.6 ; \mathrm{Br}$, 12.9. Found: C, 70.9; H, 7.9; Br, 12.8 .

3-\{4-[(3,5-Di-tert-butyl-4-acetoxyphenyl)(3,5-di-tertbutyl-4-oxo-cyclohexa-2,5-diene-1-ylidene) methyl]phenyl thiophene (2a). 3-Thiopheneboronic acid (Aldrich) $(0.68 \mathrm{~g}, 5.33 \mathrm{mmol})$ and $3 \mathrm{a}(3.0 \mathrm{~g}, 4.84 \mathrm{mmol})$ were dissolved in 1,2-dimethoxyethane $(10.2 \mathrm{~mL})$. To the solution was added tetrakis(triphenylphosphine)palladium $(0)(0.352 \mathrm{~g}, 0.305 \mathrm{mmol})$ and $2 \mathrm{~N}$ sodium carbonate $(10.2 \mathrm{~mL})$, and the solution was stirred $95^{\circ} \mathrm{C}$ for $24 \mathrm{~h}$ under a nitrogen atomsphere, cooled to room temperature, and then the organic layer was extracted with ether, washed with water, and dried over anhydrous sodium sulfate. The ether layer was evaporated, and the crude product was purified by chromatography on silica gel with a hexane/chloroform (1/2) eluent. It was recrystallized from hexane/chloroform to give the title compound as orange crystals: yield $72 \%$; Mp $298-299^{\circ} \mathrm{C} ;{ }^{1} \mathrm{H} \mathrm{NMR}\left(\mathrm{CDCl}_{3}, 500 \mathrm{MHz}\right): \delta 1.26$ (s, $9 \mathrm{H}$, quinone tert- $\mathrm{Bu}), 1.27(\mathrm{~s}, 9 \mathrm{H}$, quinone tert $-\mathrm{Bu})$, $1.32(\mathrm{~s}, 18 \mathrm{H}$, tert $-\mathrm{Bu}), 2.37\left(\mathrm{~s}, 3 \mathrm{H}, \mathrm{OCOCH}_{3}\right), 7.19(\mathrm{~s}$, $2 \mathrm{H}, \mathrm{Ph}), 7.20(\mathrm{~d}, 1 \mathrm{H}, 2.5 \mathrm{~Hz}$, quinone), $7.25(\mathrm{~d}, 1 \mathrm{H}$, $2.5 \mathrm{~Hz}$, quinone), 7.31 (d, 2H, $8.0 \mathrm{~Hz}, \mathrm{Ph}), 7.43$ (q, $1 \mathrm{H}, 2.8,4.8 \mathrm{~Hz}, \mathrm{Th}), 7.49$ (q, 1H, 1.3, $5.2 \mathrm{~Hz}, \mathrm{Th})$, 7.59 (q, $1 \mathrm{H}, 1.5,3.0 \mathrm{~Hz}, \mathrm{Th}), 7.66(\mathrm{~d}, 2 \mathrm{H}, 7.9 \mathrm{~Hz}$, $\mathrm{Ph}) ;{ }^{13} \mathrm{C} \mathrm{NMR}\left(\mathrm{CDCl}_{3}\right): \delta 22.67,29.58,29.64,35.31$, 35.32, 35.56, 121.14, 125.69, 126.12, 125.63, 129.74, $130.61,132.94,136.43,137.48,141.42,142.22$, 147.37, 149.17, 156.15, 170.64, 186.23.; IR ( $\mathrm{KBr}$ pellet, $\left.\mathrm{cm}^{-1}\right): 3098\left(v_{\text {thiophene }} \beta \mathrm{C}-\mathrm{H}\right), 1755$ (acetyl, $v_{\mathrm{C}=\mathrm{O}}$ ), 1603 (quinone, $v_{\mathrm{C}=\mathrm{C}}$ ). $\mathrm{MS}(\mathrm{m} / \mathrm{z}): 622\left(\mathrm{M}^{+}\right)$, calcd for $\mathrm{M}=622.9$. Anal. Calcd for $\left(\mathrm{C}_{41} \mathrm{H}_{50} \mathrm{O}_{3} \mathrm{~S}\right)$ : $\mathrm{C}$, 79.1; H, 8.1; S, 5.2. Found: C, 78.6; H, 8.4; S, 5.1.

3-\{4-[(3,5-Di-tert-butyl-4-hydroxyphenyl)(3,5-di-tertbutyl-4-oxo-cyclohexa-2,5-diene-1-ylidene)methyl]phenyl\} thiophene (2b). 2a $(0.361 \mathrm{~g}, 0.580 \mathrm{mmol})$ was dissolved in a slight amount of THF, and it was mixed with DMSO $(40 \mathrm{~mL})$. To the formed suspension was added $2.5 \mathrm{~N}$ potassium hydroxide $(17 \mathrm{~mL})$. The solution was stirred at $50^{\circ} \mathrm{C}$ for $15 \mathrm{~h}$, and neutralized 
with $1 \mathrm{~N}$ hydrochloric acid. The product was extracted with chloroform, and washed with water, and dried over anhydrous sodium sulfate. The organic layer was evaporated and the crude was recrystallized from hexane/chloroform (8/2) to give the title compound as orange crystals: yield $81 \%$; Mp 246.0-246.6 ${ }^{\circ} \mathrm{C} ;{ }^{1} \mathrm{H} \mathrm{NMR}$ $\left(\mathrm{CDCl}_{3}, 500 \mathrm{MHz}\right): \delta 1.26(\mathrm{~s}, 9 \mathrm{H}$, quinone tert-Bu), $1.29(\mathrm{~s}, 9 \mathrm{H}$, quinone tert $-\mathrm{Bu}), 1.42(\mathrm{~s}, 18 \mathrm{H}$, tert $-\mathrm{Bu})$, $5.51(\mathrm{~s}, 1 \mathrm{H}, \mathrm{OH}), 7.06(\mathrm{~s}, 2 \mathrm{H}, \mathrm{Ph}), 7.21(\mathrm{~d}, 1 \mathrm{H}, 2.5 \mathrm{~Hz}$, quinone), $7.25(\mathrm{~d}, 1 \mathrm{H}, 2.5 \mathrm{~Hz}$, quinone), $7.32(\mathrm{~d}, 2 \mathrm{H}$, $8.0 \mathrm{~Hz}, \mathrm{Ph}), 7.44$ (q, 1H, 2.8, $4.8 \mathrm{~Hz}, \mathrm{Th}), 7.50$ (q, $1 \mathrm{H}$, $1.3,5.2 \mathrm{~Hz}, \mathrm{Th}), 7.60$ (q, $1 \mathrm{H}, 1.5,3.0 \mathrm{~Hz}, \mathrm{Th}), 7.67$ $(\mathrm{d}, 2 \mathrm{H}, 7.9 \mathrm{~Hz}, \mathrm{Ph}) ;{ }^{13} \mathrm{C} \mathrm{NMR}\left(\mathrm{CDCl}_{3}, \mathrm{ppm}\right): \delta 29.57$, $29.68,30.34,34.41,35.30,121.06,125.57,125.63$, $126.15,126.61,128.86,130.14,131.88,132.50$, $133.10,135.33,136.37,139.96,141.51,146.67$, 155.53, 157.81, 186.11.; IR ( $\mathrm{KBr}$ pellet, $\mathrm{cm}^{-1}$ ): 3634 $\left(v_{\mathrm{O}-\mathrm{H}}\right), 3095\left(v_{\text {thiophene }} \beta \mathrm{C}-\mathrm{H}\right), 1603$ (quinone, $\left.v_{\mathrm{C}=\mathrm{C}}\right)$; $\mathrm{MS}(\mathrm{m} / \mathrm{z}): 581\left(\mathrm{M}^{+}\right)$, calcd for $\mathrm{M}=580.9$. Anal. Calcd for $\left(\mathrm{C}_{39} \mathrm{H}_{48} \mathrm{O}_{2} \mathrm{~S}\right): \mathrm{C}, 80.6$; H. 8.3; $\mathrm{S}, 5.5$. Found: $\mathrm{C}$, 80.2; H. 8.6; S, 5.4.

Polymerization. Ferric chloride $(0.31 \mathrm{~g}, 1.91 \mathrm{mmol})$ was suspended in a chloroform solution $(96.3 \mathrm{~mL})$ of 2a $(0.30 \mathrm{~g}, 0.482 \mathrm{mmol})$. The resulting red purple mixture was stirred for $24-200 \mathrm{~h}$ at $-30^{\circ} \mathrm{C}$ - room temperature under nitrogen. The reaction mixture was poured into methanol, and the orange colored precipitate was collected and washed several times with water and methanol. The precipitate was dissolved in THF and poured again into methanol. The orange precipitate was washed with hot methanol, acetone, and hexane using a Soxhlet extractor, and redissolved in hot dichloromethane. The dichloromethane solution was poured into methanol to give a purified polymer of 1a: yield $67 \%,{ }^{1} \mathrm{H} \mathrm{NMR}\left(\mathrm{CDCl}_{3}, 500 \mathrm{MHz}\right) \delta 1.34(\mathrm{~s}$, $18 \mathrm{H}$, tert-butyl), $2.35\left(\mathrm{~s}, 3 \mathrm{H},-\mathrm{OCOCH}_{3}\right), 6.90-7.30$ $(\mathrm{m}, 9 \mathrm{H}, \mathrm{Th}, \mathrm{Ph}) ;{ }^{13} \mathrm{C} \mathrm{NMR}\left(\mathrm{CDCl}_{3}\right) \delta 22.26,31.49$, $35.52,127.45,129.50,131.18,132.30,134.37,139.88$, 142.43, 147.46, 170.92.; IR $\left(\mathrm{KBr}, \mathrm{cm}^{-1}\right) 1767\left(v_{\mathrm{C}=\mathrm{O}}\right)$, 1610 (quinone $v_{\mathrm{C}=\mathrm{C}}$ ). $\quad T_{\mathrm{d} 10 \%}: 460^{\circ} \mathrm{C} . T_{\mathrm{g}}:-4.3^{\circ} \mathrm{C}$. Anal. Calcd for $\left(\mathrm{C}_{41} \mathrm{H}_{48} \mathrm{O}_{3} \mathrm{~S}\right)_{n}: \mathrm{C}, 79.4 ; \mathrm{H}, 7.7 ; \mathrm{S}$, 5.2. Found: $\mathrm{C}, 79.8 ; \mathrm{H}, 7.8 ; \mathrm{S}, 5.0$. Molecular weight of the polymer was measured by GPC (Tosoh LS-8000, polystyrene-gel column, THF eluent at $40^{\circ} \mathrm{C}$, polystyrene calibration).

Poly(3-\{4-[(3,5-di-tert-butyl-4-hydroxyphenyl) (3,5-ditert-butyl-4-oxocyclohexa-2,5-diene-1-ylidene)methyl]phenyl\} thiophene] (1b). 1a (199 mg) was dissolved in a slight amount of THF. It was suspended in DMSO $(31 \mathrm{~mL})$ and $2.5 \mathrm{~N}$ potassium hydroxide $(1.5 \mathrm{~mL})$ was added. The solution was stirred at $45^{\circ} \mathrm{C}$ for $12 \mathrm{~h}$ under a nitrogen atmosphere and neutralized with $1 \mathrm{~N}$ hydrochloric acid. The product was extracted with chloroform, washed with water, and dried over anhydrous sodium sulfate. The organic layer was evaporated, and the solution was poured into methanol to yield a orange-colored powder of $\mathbf{1 b}(176 \mathrm{mg})$ : yield 95\%; ${ }^{1} \mathrm{HNMR}\left(\mathrm{CDCl}_{3}, 500 \mathrm{MHz}\right) \delta 1.15$ (s, $9 \mathrm{H}$, quinone tert-Bu), $1.29(\mathrm{~s}, 9 \mathrm{H}$, quinone tert $-\mathrm{Bu})$, $1.36(\mathrm{~s}, 18 \mathrm{H}$, tert $-\mathrm{Bu}) 5.46(\mathrm{~s}, 1 \mathrm{H}, \mathrm{OH}), 6.80-7.15$ $(\mathrm{m}, 9 \mathrm{H}, \mathrm{Th}, \mathrm{Ph}) ;{ }^{13} \mathrm{CNMR}\left(\mathrm{CDCl}_{3}, \mathrm{ppm}\right) \delta 30.37$, $34.40,125.99,126.59,129.35,130.08,135.76,140.30$, 144.90, 153.52.; IR $\left(\mathrm{KBr}, \mathrm{cm}^{-1}\right) 3633\left(v_{\mathrm{O}-\mathrm{H}}\right), 1607$ (quinone $v_{\mathrm{C}=\mathrm{C}}$ ). $\quad T_{\mathrm{d} 10 \%}: 403^{\circ} \mathrm{C} . T_{\mathrm{g}}:-12.6^{\circ} \mathrm{C}$. Anal. Calcd for $\left(\mathrm{C}_{39} \mathrm{H}_{46} \mathrm{O}_{2} \mathrm{~S}\right)_{n}$ : C, 81.0; H, 8.0; S, 5.5. Found: $\mathrm{C}, 81.3 ; \mathrm{H}, 7.7 ; \mathrm{S}, 5.6$.

Oxidation. A small excess of sodium hydroxide solution $(1 \mathrm{~mL})$ was added to a toluene solution $(2 \mathrm{~mL})$ of 1b $\left(23.5 \mathrm{mg}, 20\right.$ unit $\left.\mathrm{mmol} \mathrm{L}^{-1}\right)$, and the solution was stirred for $0.5 \mathrm{~h}$ under a nitrogen atmosphere. The solution was then vigorously stirred with $1 \mathrm{~mL}$ of aqueous potassium ferricyanide $(13.1 \mathrm{mg}, 12$ equiv. to the galvinoxy unit) at room temperature. The solution rapidly turned red-brownish after $30 \mathrm{~min}$, which was ascribed to the galvinoxyl radical formation. The organic layer was washed with water and dried over anhydrous sodium sulfate to give a toluene solution of $\mathbf{1}$. The corresponding monomeric radical $\mathbf{2}$ was also generated from $\mathbf{2 b}$ using the same procedure.

Electrochemical Measurements. A voltammetric investigation was carried out in dichloromethane in the presence of $0.1 \mathrm{M}$ tetra- $n$-butylammonium tetrafluoroborate as a supporting electrolyte and a small amount of tetra- $n$-butylammoniumhydroxide as an alkaline with a platinum working electrode using a function generator (Nikko Keisoku NPG-3) and a potentiogalvanostat (NPGS-301) at a scan rate from 100 to $25 \mathrm{mV}$. Electrolytical UV measurements were carried out using a platinum mesh electrode, under the controlled-potential determined by the cyclic voltammetry.

Magnetic Measurement. Toluene solutions of the galvinoxyl polymer were immediately transferred to a diamagnetic capsule after the oxidation. The samples, diluted with diamagnetic polystyrene, were also prepared as described previously. ${ }^{3}$ Magnetization and static magnetic susceptibility were measured with a Quantum Design MPMS-7 SQUID magnetometer. The magnetization was measured from 0.1 to $7 \mathrm{~T}$ at 1.8, 2.0, $2.5,3$, and $5 \mathrm{~K}$. The static magnetic susceptibility was measured from 2 to $200(300) \mathrm{K}$ at a field of $0.5 \mathrm{~T}$.

NMR Magnetic Susceptibility. A $20 \mathrm{mM} \mathrm{CDCl}_{3}$ solution of 1 containing $0.1 \%$ tetramethylsilane (TMS) was prepared by chemical oxidation with alkaline potassium ferricyanide. By successive dilution, 10, 5, and $2.5 \mathrm{mM}$ solutions of $\mathbf{1}$ were also prepared. These solutions were loaded into NMR tubes $(\phi 1.5 \mathrm{~mm})$, and 
each tube was then placed in a NMR tube $(\phi 5.0 \mathrm{~mm})$ containing $0.5 \mathrm{~mL}$ of the $\mathrm{CDCl}_{3}$ solution containing $0.1 \%$ TMS. The ${ }^{1} \mathrm{HNMR}$ spectrum was recorded on a 499.22825 MHz NMR spectrometer (JEOL Lambda 500). Magnetic susceptibility was calculated from the induced paramagnetic shift of the TMS, according to the Evans equation. ${ }^{14}$

Other Measurements. ESR spectra were taken using a JEOL JES-TE200 ESR spectrometer with 100$\mathrm{kHz}$ field modulation. The spin concentration of each sample was determined based on the assumption of $S=1 / 2$ by careful integration of the ESR signal standardized with that of a TEMPO $(2,2,6,6$-tetramethylpiperidine-1-oxyl) solution. Thermal analyses were performed over a temperature range from 25 to $600^{\circ} \mathrm{C}$ for thermogravimetry and over a temperature range of -50 to $550^{\circ} \mathrm{C}$ with a heating rate of $8^{\circ} \mathrm{C} \mathrm{min}^{-1}$ for differential scanning calorimetry with a Seiko DSC 5200. Intrinsic viscosity of the toluene solution of the polymer was measured at $25^{\circ} \mathrm{C}$ using an Ubbelohde viscometer. Electrical conductivity was measured by a four-probe technique. The doping was carried out using iodine vapor in vacuo (ca. $10 \mathrm{mmHg}$ ) for $24 \mathrm{~h}$.

\section{RESULTS AND DISCUSSION}

Oxidative Polymerization and Polymer Characterization. 4-Bromo-[(3,5-di-tert-butyl-4-hydroxyphenyl)(3,5-di-tert-butyl-4-oxocyclohexa-2,5-diene-1-ylidene)methyl]benzene (3b) was prepared by a condensation of methyl 4-bromobenzoate ${ }^{3 \mathrm{c}, 13 \mathrm{a}}$ as the starting material with (2,6-di-tert-butyl-4-lithiophenoxy) trimethylsilane. ${ }^{3 a}$ The phenolic hydroxy group was protected with an acetyl group which is appropriate for both the following Suzuki coupling ${ }^{15}$ and oxidative polymerization. The acetyl-protected galvinoxy moiety was introduced at the 3-position of the thiophene ring via Suzuki coupling reaction to give $3-\{4-[(3,5$-di-tert-butyl-4acetoxyphenyl)(3,5-di-tert-butyl-4-oxo-cyclohexa-2,5diene-1-ylidene)methyl]phenyl thiophene (2a). The acetoxy-protected $\mathbf{2 a}$ was converted to the corresponding hydroxy $\mathbf{2 b}$ in alkaline solution (Scheme 1).

2a was oxidatively polymerized with 4 equivalents of ferric chloride in dilute chloroform solution and at low temperature to yield 1a. Copolymerization of $\mathbf{2 a}$ with 3-(3,5-di-tert-butyl-4-acetoxyphenyl)thiophene (5) and 3-hexylthiophene (6) was also carried out under the same conditions to give the corresponding copolymer (7a and 8a, respectively). The reaction mixture was poured into methanol, and the precipitated polymer was washed with water and methanol to remove the ferric ion. The reprecipitated polymer was washed again with hot methanol, hexane, and acetone, succes-

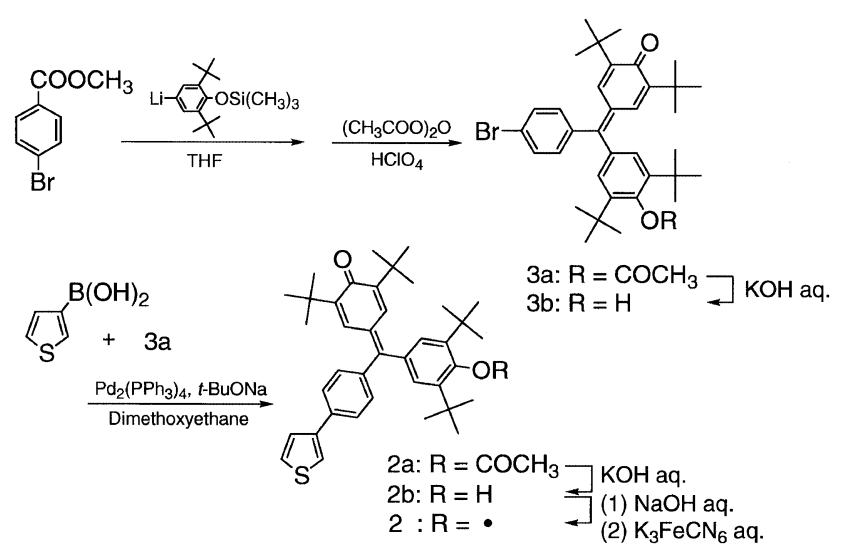

Scheme 1.

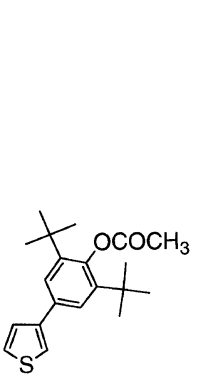

5

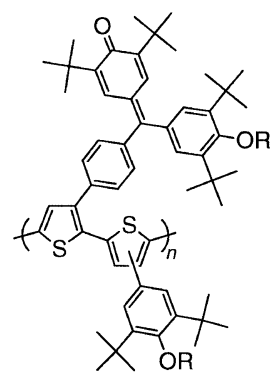

7a: $\mathrm{R}=\mathrm{COCH}_{3}$
$7 \mathrm{~b}: \mathrm{R}=\mathrm{H}$

$7 \mathrm{~b}: \mathrm{R}=\mathrm{H}$
$7: \mathrm{R}=$.

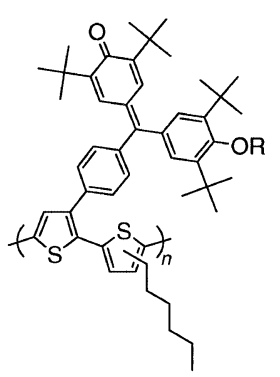

8a: $\mathrm{R}=\mathrm{COCH}_{3}$

$8 b: R=H$

$8: R=$.
Chart 2.

sively, using a Soxhlet extractor and reprecipitated from dichloromethane to methanol. Poly(3-\{4-[(3,5-di-tertbutyl-4-acetoxyphenyl)(3,5-di-tert-butyl-4-oxocyclohexa-2,5-diene-1-ylidene) methyl]phenyl thiophene) (1a) was obtained as an orange powder. This purification procedure completely removed ferric chloride from the product and dedoped the polymer. The polymer was soluble in common solvents such as benzene, toluene, THF, and dichloromethane (Chart 2).

The regioregular or head-to-tail-linked polymer structure was characterized by NMR spectroscopy. The regioregularity or head-to-tail content of 1a was estimated using the integration of the ${ }^{1} \mathrm{H} N \mathrm{NR}$ of the aromatic $\beta$-thiophene and phenyl groups. The polymerization of $5 \mathrm{mM} 2 \mathrm{a}$ at $-30^{\circ} \mathrm{C}$ yielded the polythiophene 1a with a molecular weight of $5.0 \times 10^{4}$ and a head-to-tail content of $92 \%$. The regularity of 1a was lower than that of poly[3-(3,5-di-tert-butyl-4acetoxyphenyl)thiophene], the acetoxy-protected 4 , obtained under the same conditions, ${ }^{11}$ probably because an electronic donating effect of the galvinoxyl group attached to the thiophene ring is weaker than that of the phenoxy-substitute of 5 (Scheme 2). ${ }^{11}$

The copolymerization of $\mathbf{2 a}$ with $\mathbf{5}$ and $\mathbf{6}$ gave the copolymer, 7a and 8a, respectively; the reactivity of $\mathbf{2 a}$ was lower than those of $\mathbf{5}$ and $\mathbf{6}$ (Table I). The acetoxyprotected polymers, 1a, 7a, and $\mathbf{8 a}$, were converted to 
Table I. Oxidative polymerization ${ }^{\mathrm{a}}$ of galvinoxyphenylthiophene (2a) and copolymerization of $\mathbf{2 a}$ with 3-phenoxythiophene (5) and 3-hexylthiophene (6)

\begin{tabular}{|c|c|c|c|c|c|c|}
\hline$\frac{\text { Monomer }}{\text { feed }^{\mathrm{e}}}$ & $\begin{array}{l}\text { Monomer } \\
\text { concn } \\
\mathrm{mM}\end{array}$ & $\frac{\text { Yield }}{\%}$ & $\frac{M_{\mathrm{n}}^{\mathrm{b}}}{10^{4}}$ & $M_{\mathrm{w}} / M_{\mathrm{n}}$ & $\frac{\text { Composition }^{\mathrm{c}}}{\mathrm{mol} \%}$ & $\frac{\mathrm{HT}^{\mathrm{d}}}{\%}$ \\
\hline \multirow[t]{3}{*}{$2 a$} & 100 & 83 & 7.8 & 2.6 & - & 84 \\
\hline & 20 & 78 & 5.6 & 2.4 & - & 88 \\
\hline & 5 & 74 & 5.0 & 2.4 & - & 92 \\
\hline $\mathbf{2 a} / \mathbf{5}(1 / 1)$ & 5 & 75 & 3.9 & 1.9 & 45 & - \\
\hline $\mathbf{2 a} / \mathbf{5}(1 / 10)$ & 5 & 78 & 7.6 & 1.8 & 11 & - \\
\hline $\mathbf{2 a} / \mathbf{6}(1 / 1)$ & 5 & 77 & 3.3 & 2.0 & 43 & - \\
\hline $\mathbf{2 a} / \mathbf{6}(1 / 10)$ & 5 & 88 & 7.3 & 2.1 & 7 & - \\
\hline
\end{tabular}

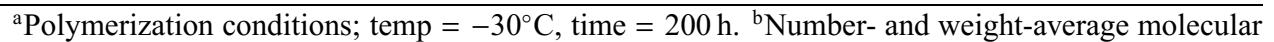
weight measured by GPC. ${ }^{\mathrm{c}}$ Molar fraction of $\mathbf{2 a}$ in the copolymer. ${ }^{\mathrm{d}} \mathrm{Head}$-to-tail content determined by the ${ }^{1} \mathrm{H}$ NMR of the thiophene unit. ${ }^{e}$ Feed molar ratio.

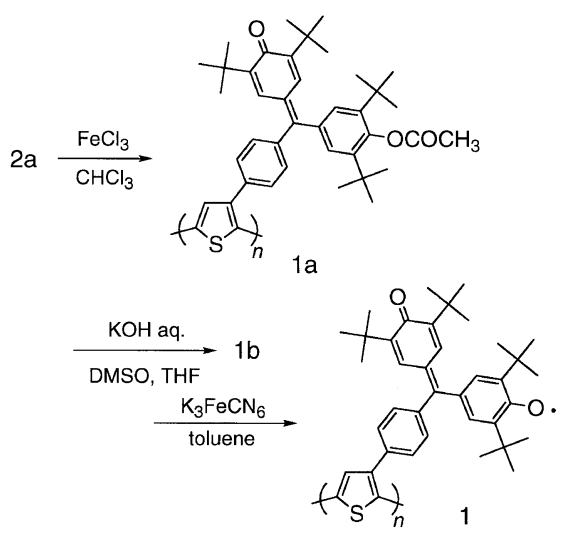

Scheme 2.

the corresponding hydroxy polymers through the elimination of the acetyl group in an alkaline solution.

The intrinsic viscosities ([ $\eta])$ of toluene solutions of $1 \mathrm{a}$ with molecular weight of $5.0 \times 10^{4}$ and $1.5 \times$ $10^{4}$ were 0.61 and $0.13 \mathrm{dL} \mathrm{g}^{-1}$, respectively. Plots of logarithmic intrinsic viscosity vs. logarithmic molecular weight of the polymer obey the classical MarkHouwink relationship and give the constants $K=$ $4.84 \times 10^{7}$ and $\alpha=1.3$. The $\alpha$ value for $\mathbf{1 a}$ is larger than those reported for poly(3-alkylthiophene)s ( $\left.\alpha=0.7-0.8^{16}\right)$, suggesting a rod-like chain due to the bulky substituent along the backbone.

UV-vis absorption spectra of $\mathbf{1 a}$ and $\mathbf{1 b}$ showed strong maxima at 408 and $417 \mathrm{~nm}$, which were ascribed to the quinoid chromophore of the galvinoxy residue similar to those of the corresponding monomers.

Radical Generation and Electrochemistry. The toluene solution of the hydroxy precursor $\mathbf{1 b}$ turned dark blue $\left(\lambda_{\max }=610 \mathrm{~nm}\right.$, see in Figure 1) by addition of a small excess of tetra- $n$-butylammonium hydroxide, which was ascribed to polyanion formation. The anion solution was heterogeneously treated with an aqueous potassium ferricyanide to yield the galvinoxyl radical derivative $\mathbf{1}$. The solution turned reddish brown through the oxidation, with appearance of new absorp-

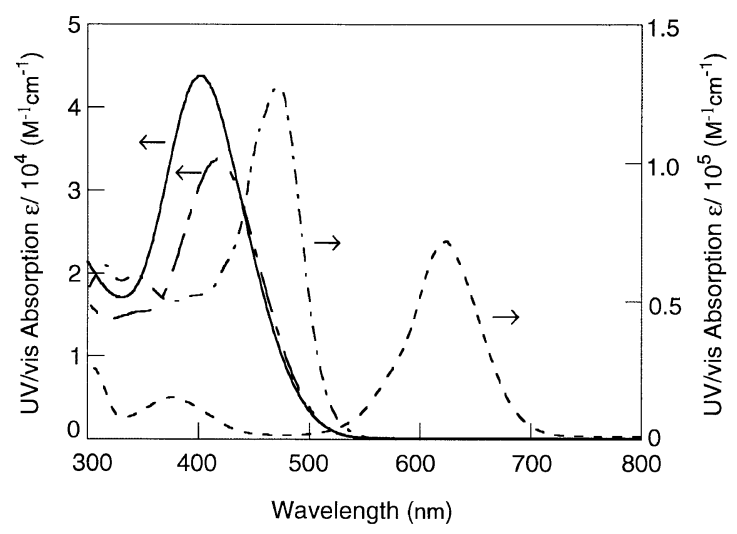

Figure 1. UV-vis absorption and fluorescence spectra of 1a $(-), \mathbf{1 b}(--), \mathbf{1 c}(---)$, and $\mathbf{1}(-\cdot-)$ in THF solution.

tion maxima at 450 and $480 \mathrm{~nm}$ for 1 with low and high spin concentration, respectively. The radical was almost quantitatively generated from $\mathbf{1 b}$ and $\mathbf{2} \mathbf{b}$ by the heterogeneous oxidation. The radicals, $\mathbf{1}$ and $\mathbf{2}$, were isolated as a red brownish powder and a dark brown crystal, respectively, which were chemically persistent at room temperature even in air (half-life time was over one month for them).

The solution ESR spectrum of the galvinoxyl monoradical 2 gave a hyperfine structure ascribed to the interaction with four equivalent protons of the galvinoxyl moiety $\left(a_{\mathrm{H}}=0.133 \mathrm{mT}\right)$ (Figure $\left.2 \mathrm{a}\right)$. The hyperfine coupling constant was comparable with that of phenylgalvinoxyl $\left(a_{\mathrm{H}}=0.134-0.135 \mathrm{mT}^{13 \mathrm{~b}}\right)$, which suggests a spin localization on the galvinoxyl part but not throughout to the thiophene ring. The hyperfine structure was broadened but still observed in the spectrum of the polyradical $\mathbf{1}$ with a low spin concentration. The ESR spectra of $\mathbf{1}$ became broader with an increase in the spin concentration, and changed to a sharp and unimodal signal (Figure $2 \mathrm{~b}$ ).

The radical derivatives were also generated by electrochemical oxidation. $\mathbf{1 b}$ and $\mathbf{2 b}$ in the alkaline dichloromethane solution gave reversible redox waves 


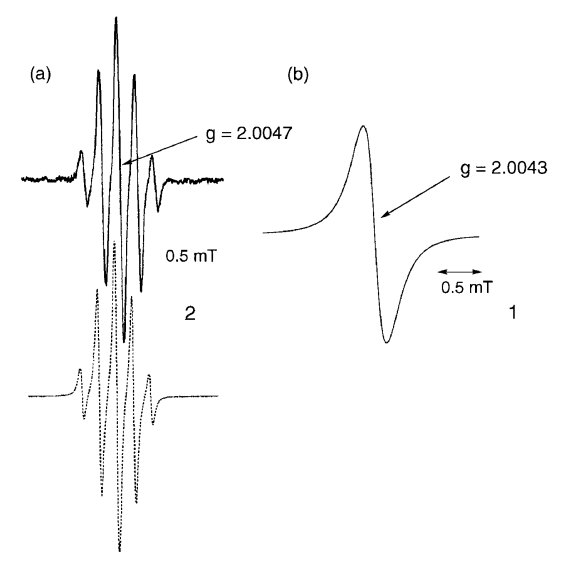

Figure 2. ESR spectra of the radicals at room temperature. (a) 2 in $0.5 \mathrm{M}$ toluene solution. The solid line for $\mathbf{2}$ with spin concn $=0.12 \mathrm{spin} /$ galvinoxyl unit and the dashed line for the simulation with $a_{\mathrm{H}}=0.133 \mathrm{mT}$. (b) 1 with spin concn $=0.93 \mathrm{spin} /$ galvinoxyl unit.

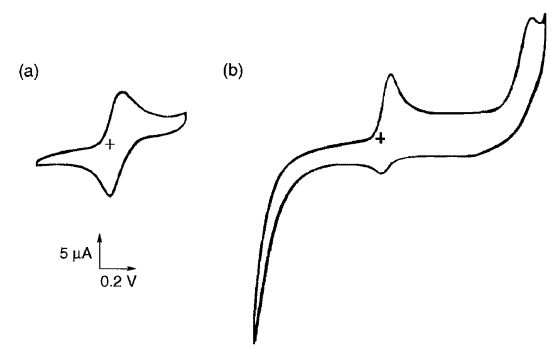

Figure 3. Cyclic voltammograms for $1 \mathrm{c}$ (a) $-0.5-0.5 \mathrm{~V}$ and (b) $-1.0-1.3 \mathrm{~V}$ in $\mathrm{CH}_{2} \mathrm{Cl}_{2}$ with $0.1 \mathrm{M}\left(\mathrm{C}_{4} \mathrm{H}_{9}\right)_{4} \mathrm{NBF}_{4}$ and $(n$ $\left.\mathrm{C}_{4} \mathrm{H}_{9}\right)_{4} \mathrm{NOH}$ (scanning rate $=50 \mathrm{mV} \mathrm{s}^{-1}$ ).

during cyclic voltammetry (Figure 3 a), which indicated the stability of these radicals at room temperature in solution. The redox potential ( $v s$. $\mathrm{Ag} / \mathrm{AgCl}$ ) was estimated to be $0.02 \mathrm{~V}$ for $1 \mathbf{b}$, which was a little higher than that of the phenolate/phenoxyl for $4\left(-0.08 \mathrm{~V}^{11}\right)$, due to stability of the quinone structure in $\mathbf{1 b}$. At the anodic potential region for $\mathbf{1 b}$, only one oxidation peak $(c a .1 .1 \mathrm{~V})$ was observed (Figure $3 \mathrm{~b}$ ). This suggests a possibility to generate both localized spins on the pendant galvinoxy moieties and a $\pi$-delocalizing spin on the polythiophene backbone, and to provide a bifunctional polyradical with multi-spins and electrical conductivity.

1b was electrochemically oxidized under the controlled potential of $0.3 \mathrm{~V}$ ( vs. $\mathrm{Ag} / \mathrm{AgCl})$ in the alkaline dichloromethane solution. Figure 4 shows the UV-vis spectral change of the $\mathbf{1 b}$ solution during the electrolysis. The absorption band of $\mathbf{1 b}$ at $610 \mathrm{~nm}$ gradually disappeared and in turn a new band appeared at $480 \mathrm{~nm}$ with an isobestic point at $524 \mathrm{~nm}$. The similar spectral change behavior was also observed in a neutral solution. The polyradical 1 possessed a reduction peak at $c a .-1.1 \mathrm{~V}(v s . \mathrm{Ag} / \mathrm{AgCl})$. This spectral change was repeatedly recorded through the oxidation and reduction (a)

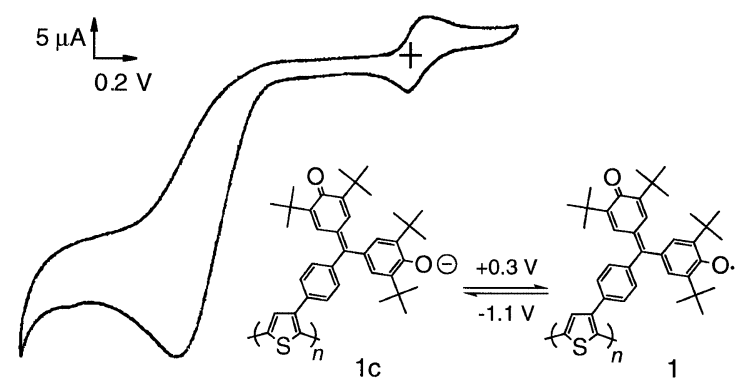

(b)

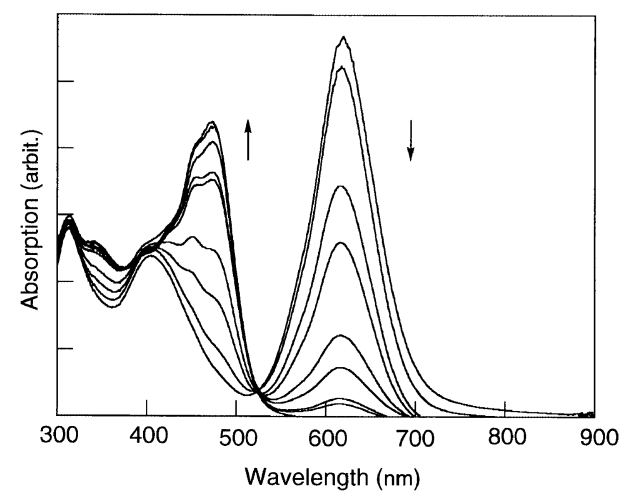

Figure 4. Cyclic voltammograms for $1 \mathrm{c}(-1.5-0.5 \mathrm{~V})$ in $\mathrm{CH}_{2} \mathrm{Cl}_{2}$ with $0.1 \mathrm{M}\left(\mathrm{C}_{4} \mathrm{H}_{9}\right)_{4} \mathrm{NBF}_{4}$ and $\left(n-\mathrm{C}_{4} \mathrm{H}_{9}\right)_{4} \mathrm{NOH}$ (scanning rate $\left.=50 \mathrm{mV} \mathrm{s}^{-1}\right)(\mathrm{a})$, and $\mathrm{UV}$-vis spectra (b) recorded during the electroreduction under controlled-potential at $-1.1 \mathrm{~V}$ and the electrooxidation at $0.3 \mathrm{~V}$ for $\mathbf{1}$, using a platinum mesh electrode in $\mathrm{CH}_{2} \mathrm{Cl}_{2}$ with $0.1 \mathrm{M}\left(\mathrm{C}_{4} \mathrm{H}_{9}\right)_{4} \mathrm{NBF}_{4}$.

cycles. That is, the potential sweep from -1.3 to $1.3 \mathrm{~V}$ displayed a reversible color change from dark blue to red brown, which is ascribed to the polyanion 1c and the polyradical $\mathbf{1}$, respectively.

Electrical Conductivity. Electrical conductivity of the polythiophene derivatives was measured on their pressed pellets. The pristine precursor polymers exhibited very low conductivity below $10^{-6} \mathrm{~S} \mathrm{~cm}^{-1}$. 1a and 1b turned from red to dark brown by the iodine doping; the doped amount was estimated from the increased weight ( $c a .18 \mathrm{wt} \%$ ). ESR spectra of the doped polymers gave a new signal at $g=2.0032\left(\Delta H_{\mathrm{PP}}=0.5 \mathrm{mT}\right)$. For the doped 1a and $\mathbf{1 b}$ no increase in electrical conductivity was observed probably because of the presence of bulky substituent group covering the polythiophene backbone and of distortion of the backbone. On the other hand, the conductivity of $\mathbf{1}$ was $2.8 \times 10^{-5} \mathrm{~S}$ $\mathrm{cm}^{-1}$ and by the subsequent iodine-doping slightly increased to $3.1 \times 10^{-5} \mathrm{~S} \mathrm{~cm}^{-1}$ (Table II).

The doped copolymers, $\mathbf{7}$ and $\mathbf{8}$, exhibited higher conductivities of $10^{-4}-10^{-3} \mathrm{~S} \mathrm{~cm}^{-1}$ than that of the doped 1. The 3-hexylthiophene residue in 8 contributed to the higher conductivity probably as a result of reduced distortion in the polythiophene backbone.

Magnetic Property. Static magnetic susceptibility 
Table II. Electrical conductivities of the polythiophenes

\begin{tabular}{|c|c|c|}
\hline Polymer & $\frac{\text { Intact }}{\mathrm{S} \mathrm{cm}^{-1}}$ & $\frac{\text { After doping }^{\mathrm{a}}}{\mathrm{S} \mathrm{cm}^{-1}}$ \\
\hline $1 a$ & $<10^{-6}$ & $<10^{-6}$ \\
\hline $1 b$ & $<10^{-6}$ & $<10^{-6}$ \\
\hline 1 & $2.8 \times 10^{-5}$ & $3.1 \times 10^{-5}$ \\
\hline $7\left(45^{b}, 0.58^{c}\right)$ & $1.5 \times 10^{-5}$ & $9.6 \times 10^{-4}$ \\
\hline $\mathbf{8}\left(43^{b}, 0.89^{c}\right)$ & $4.2 \times 10^{-5}$ & $4.5 \times 10^{-3}$ \\
\hline
\end{tabular}

${ }^{\mathrm{a}}$ Doping with iodine. ${ }^{\mathrm{b}}$ Molar fraction of $\mathbf{2 a}$ in the copolymer. ${ }^{\mathrm{c}}$ Spin concentration (spin/phenol unit).

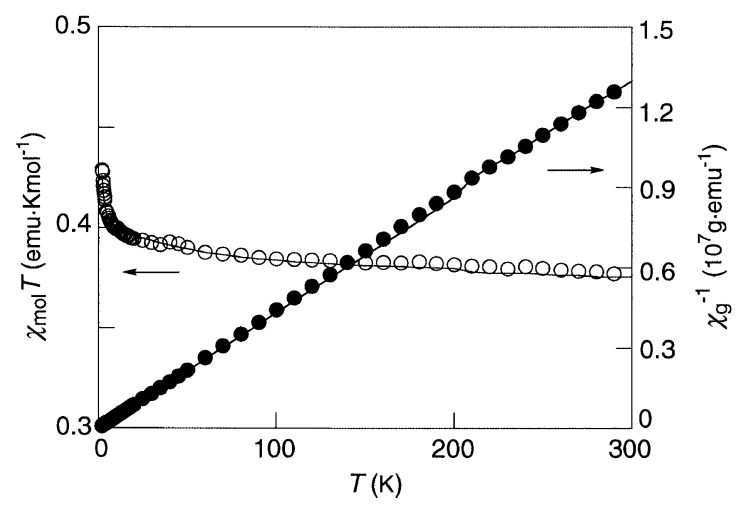

Figure 5. Temperature dependence of molar magnetic susceptibility $\left(\chi_{\text {mol }}\right)$ and $T(\bigcirc)$ and reciprocal magnetic susceptibility $(1 / \chi)(\mathcal{)})$ for the neat sample of 2 with spin concn $=0.93$ spin/galvinoxyl unit.

and magnetization of the radical derivatives were measured with a SQUID magnetometer. Magnetic susceptibility of the polycrystalline powder of the monoradical 2 followed a Curie-Weiss law $\left(\chi=C /\left(T-\theta_{\mathrm{w}}\right)\right)$ over 2-300 K temperature range (Figure 5). The Curie constant $(C)$ and Weiss temperature $\left(\theta_{\mathrm{w}}\right)$ were $2.2 \times 10^{-5}$ emu K g ${ }^{-1}$ and $+0.15 \mathrm{~K}$, respectively. The spin concentration estimated from the Curie constant was 0.93 spin/galvinoxyl unit, and well consistent with that estimated by the integration of the ESR signal ( 0.95 spin/galvinoxyl unit). Plots of the product of molar magnetic susceptibility $\left(\chi_{\mathrm{mol}}\right)$ and $T$ vs. $T$ are also shown in Figure 5. The $\chi_{\mathrm{mol}} T$ value was deviated slightly upward from the theoretical value, $\chi_{\mathrm{mol}} T=$ $0.375 \mathrm{emu} \mathrm{K} \mathrm{mol}^{-1}$ for $S=1 / 2$, with decreasing temperature (lower than $35 \mathrm{~K}$ ), suggesting a ferromagnetic intermolecular interaction between the spins at low temperature.

Magnetization plots of the powder polyradical 1 with a spin concentration of $0.91 \mathrm{spin} /$ galvinoxyl unit were almost on the curve of $S=1 / 2$ at 2-5 K temperature range (Figure 6). The $\chi_{\mathrm{mol}} T$ vs. $T$ plots followed a Curie-Weiss law over the temperature range. Downward deviation from the theoretical value for $S=1 / 2$ below $30 \mathrm{~K}$ suggests an antiferromagnetic (probably through-space interpolymer) interaction, since the solu-

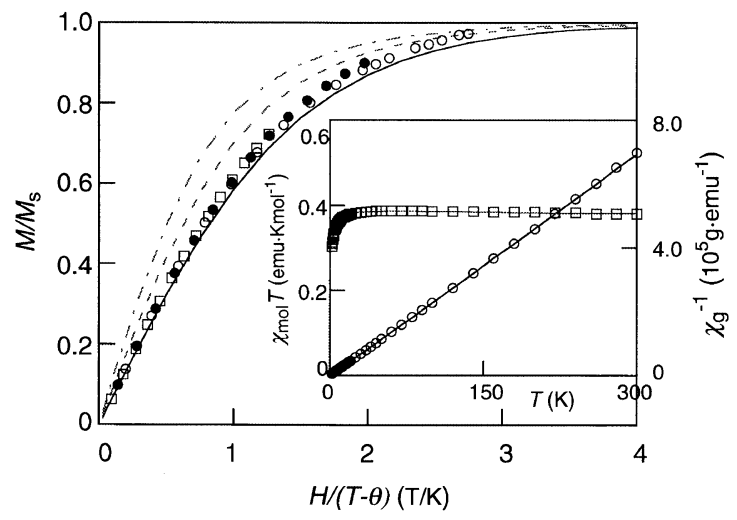

Figure 6. Normalized plots of magnetization $\left(M / M_{\mathrm{s}}\right)$ vs. the ratio of magnetic field and temperature $(H /(T-\theta))$ for the polyradical 1 with spin concn $=0.9 \mathrm{spin} /$ galvinoxyl unit in toluene at $T=2.0(\bigcirc), 3.0(\bigcirc), 5(\square) \mathrm{K}$, and the theoretical curves corresponding to the $S=1 / 2,2 / 2$, and $3 / 2$ Brillouin functions. Insert: $\chi_{\mathrm{mol}} T$ vs. $T$ plots (dashed line is the curve fitting the modified Bleaney-Bowers expression ${ }^{3}$ ) and $1 / \chi_{\mathrm{g}} v s . T$ plots (solid line for the Curie law) of 1 diluted with toluene.

tion sample of 1 exhibited the reduced an antiferromagnetic interaction. Although we succeeded in the quantitative radical generation for the polythiophene-based galvinoxyl (a spin concentration of 0.9 spin/galvinoxyl unit), the expected spin-alignment or ferromagnetic behavior was not successful for $\mathbf{1}$. From these results it is probable that the spin is localized on the pendant galvinoxyl moiety and does not distribute into the entire macromolecule. It was supported by susceptibility measurement of the $\mathrm{CDCl}_{3}$ solution of $\mathbf{1}$ at $298 \mathrm{~K}$ with ${ }^{1}$ HNMR based on the Evans method. The shift of 1 yielded the effective magnetic moment $\left(\mu_{\text {eff }}\right)$ values; 1.78 for $\mathbf{1}$ and 1.73 for $\mathbf{2}$. Theoretical $\mu_{\text {eff }}$ value for a singlet $(S=1 / 2)$ molecule is $1.73,{ }^{17}$ suggesting that the spins are independent from each other at room temperature.

Acknowledgment. This work was partially supported by a Grant-in-Aid for Scientific Research (No. 13450384) from the Ministry of Education, Culture, Sports, Science and Technology and the NEDO Project on Technology for Novel High-Functional Materials. One of the authors (M. M.) expresses his thanks for the Research Fellowship of the Japan Society for the Promotion of Science for Young Scientists.

\section{REFERENCES}

1. a) P. M. Lahti, "Magnetic Properties of Organic Materials," Marcel Dekker, Inc., New York, N.Y., 1999.

b) K. Ito and M. Kinoshita, "Molecular Magnetism - New Magnetic Materials," Kodansha and Gordon and Breach Science Publishers, Tokyo and Amsterdam, 2000.

2. a) N. Yoshioka, H. Nishide, T. Kaneko, H. Yoshiki, and E. 
Tsuchida, Macromolecules, 25, 3838 (1992).

b) H. Nishide, T. Kaneko, N. Yoshioka, H. Akiyama, M. Igarashi, and E. Tsuchida, Macromolecules, 26, 4567 (1993). c) H. Nishide, T. Kaneko, M. Igarashi, E. Tsuchida, N. Yoshioka, and P. M. Lahti, Macromolecules, 27, 3082 (1994).

3. a) H. Nishide, T. Kaneko, T. Nii, K. Katoh, E. Tsuchida, and P. M. Lahti, J. Am. Chem. Soc., 118, 9695 (1996).

b) H. Nishide, T. Kaneko, S. Toriu, Y. Kuzumaki, and E. Tsuchida, Bull. Chem. Soc. Jpn., 69, 499 (1996).

c) H. Nishide, Y. Hozumi, T. Nii, and E. Tsuchida, Macromolecules, 30, 3986 (1997).

4. a) Y. Miura, Y. Ushitani, K. Inui, Y. Teki, T. Takui, and K. Itoh, Macromolecules, 26, 3698 (1993).

b) H. Oka, T. Tamura, Y. Miura, and Y. Teki, J. Mater. Chem., 9, 1227 (1999).

c) H. Oka, T. Tamura, Y. Miura, and Y. Teki, Polym. J., 31, 979 (1999).

5. a) T. Yamamoto and H. Hayashi, J. Polym. Sci., Polym. Chem. Ed., 35, 463 (1997).

b) H. Hayashi and T. Yamamoto, Macromolecules, 30, 330 (1997).

c) H. Hayashi and T. Yamamoto, Macromolecules, 31, 6063 (1998).

6. C. Xie and P. M. Lahti, J. Polym. Sci., Part A: Polym. Chem., 37, 779 (1999).

7. D. Fichou, "Handbook of Oligo- and Polythiophene," John Wiley \& Sons, Inc., New York, N.Y., 1999.

8. a) R. D. McCullough and R. D. Lowe, J. Chem. Soc., Chem. Comm., 70 (1992).

b) T.-A. Chen, X. Wu, and R. D. Rieke, J. Am. Chem. Soc.,
117, 233 (1995).

c) S. Guillerez and G. Bidan, Synthetic Metals, 93, 123 (1998).

9. M. R. Andersson, D. Selse, M. Berggren, H. Jarvinen, T. Hjertberg, O. Ingänas, O. Wennerstrom, and J.-E. Österhorm, Macromolecules, 27, 6503 (1994).

10. S. Amou, O. Haba, K. Shirato, T. Hayakawa, M. Ueda, K. Takeuchi, and M. Asai, J. Polym. Sci., Part A: Polym Chem., 37, 1943 (1999).

11. M. Miyasaka, T. Yamazaki, E. Tsuchida, and H. Nishide, Macromolecules, 33, 8211 (2000).

12. M. Miyasaka, T. Yamazaki, E. Tsuchida, and H. Nishide, Polyhedron, 20, 1157 (2001).

13. a) W. Harrer, H. Kurreck, J. Reusch, and W. Gierke, Tetrahedron, 31, 625 (1975).

b) K. Mukai, Bull. Chem. Soc. Jpn., 48, 2405 (1975).

c) K. Awaga, T. Sugano, and M. Kinoshita, J. Chem. Phys., 85, 2211 (1986).

14. a) D. F. Evans, J. Chem. Soc., 2003 (1959).

b) S. K. Sur, J. Magn. Reson., 82, 169 (1989).

c) K. R. Stickley, T. D. Selby, and S. C. Blackstock, J. Org. Chem., 62, 448 (1997).

15. N. Miyaura and A. Suzuki, Chem. Rev., 95, 2457 (1995).

16. a) X. Bi, Q. Ying, and R. Qian, Makromol. Chem., 193, 2905 (1992).

b) T. Yamamoto, D. Oguro, and K. Kubota, Macromolecules, 29, 1833 (1996).

17. R. L. Carlin, "Magnetochemistry," Springer-Verlag GmbH \& Co., Berlin, 1986. 